LEIIENBHRG; H. Conditioned acceleration and conditioned suppression in pigeons. Journal of the Ixperimental Analysis of Bchavior, 1966, $9,205-212$.

LIITENBIRC;, H., BIRTSCH, G. J., \& COUGHLIN, R. C. "Time-out from positive reinforcement" as the UCS in a CER paradigm with rats. Psychonomic Science, 1968, 13, 3-4.
NOTES

1. I his research was supported by NIMH Grant 08430 and by the ('niversity of WisconsinMilwaukee Graduate School.

2. Trenholme, I., Baron, A., \& Kaufman, A. Iffects of signalled time-out from and loss of monetary reinforecment on human operant behavior. Unpublished study.

\title{
Schedule-induced nitrogen "drinking" in the rat
}

DEREK B. TAYLOR and DA VID LESTER, Center of Alcohol Studies, Rutgers-The State University, New Brunswick, N.J. 08903

Rats working on an FI60 food reinforcement schedule with lick-contingent nitrogen puffs available from a drinking spout exhibited interpellet "drinking" similar to schedule-induced polydipsia. The data were interpreted in terms of a thirst-adventitious reinforcement interaction; the implications for other schedule-induced behaviors were discussed.

Rats bar pressing on an intermittent schedule of food reinforcement drink large quantities of water (schedule-induced polydipsia, SIP) in bursts of drinking after each pellet. Water intake during a 3.17 h session may be three to four times the 24-h normal (Falk, 1961). Another heretof ore unrelated phenomenon is "air drinking" (Hendry \& Rasche, 1961): thirsty rats lick persistently at an air stream or to obtain air puffs contingent upon licking. Our study demonstrates that the conditions producing SIP will also evoke interpellet "air drinking."

\section{METHOD}

The Ss, three experimentally naive, male albino Sprague-Dawley rats, aged 120 to 150 days, weighing 370,400 , and $460 \mathrm{~g}$, were tested in a Grason-Stadler operant chamber enclosed in a sound-attenuated box, containing a lever and a food cup in one wall. A metal drinking spout, wired to record licking, was next to the food cup; its tip, recessed behind a plastic shield, allowed contact only with S's tongue, assuring accurate registration. The spout could deliver nitrogen puffs or water; with nitrogen, contact opened a solenoid valve for $120 \mathrm{msec}$ allowing a flow of $9100 \mathrm{ml} / \mathrm{min}$ of nitrogen, about $18 \mathrm{ml} / \mathrm{puff}$. The operations were programmed with
Digital Equipment Corporation logic. A cumulative recorder provided visual records of licking and reinforcements.

The Ss were given two 20-min sessions in the operant chamber after $23.5 \mathrm{~h}$ of water deprivation, with water available at the spout to learn its location and speed the later development of nitrogen "drinking." Next, the Ss licked for nitrogen during five daily $30-\mathrm{min}$ sessions after $23.5 \mathrm{~h}$ of water deprivation. (Pilot data showed identical performance with nitrogen and air.) During both water and nitrogen training sessions, the bar was inoperable, food being available ad lib in the home cage. Two days of ad lib food and water then followed in the home cage. Body weight was next reduced $20 \%$ by underfeeding and the $S s$ were shaped to bar press for $45-\mathrm{mg}$ food pellets. Nitrogen was available during shaping and subsequent sessions: water, never available in the chamber, was available ad lib in the home cage. After shaping, the Ss were run for one 100-pellet session on CRF, then moved gradually up to Fl60 (sec) during one 120-pellet session. Nine 120-pellet FI60 sessions followed. Home-cage water consumption was measured in the $30-\mathrm{min}$ period preceding and following the FI60 sessions.

\section{RESULTS \\ Rat AD2}

Row 1, Fig. 1, shows a licking record sample from the shaping session. A few long "drinks" are separated by many pellets. As the $S$ moved from CRF to FI60 (Row 2), long "drinks" are more frequently interspersed among many pellets. In the first full session on FI60 (Row 3), interpellet "drinking" suddenly appears, characterized by an alternating sequence of licking and bar pressing, repeated until one of the bar presses yielded a pellet. as if $S$ were pausing during drinking to "test" the bar. Gradually "drinking" bursts lengthened and "bar testing" decreased (Row 4, Session 9 on Fl(60).

\section{Rat AD3}

Rat AD3 did not "drink" during shaping or the CRF sessions. Row 1, Fig. 2, shows the session when $S$ moved from CRF to Fl60. There are occasional "drinks," and a seeming interpellet "drinking" pattern emerges finally. In the first full session on FI60 (Row 2), there is a definite interpellet "drinking" pattern, although with short bursts. "Bar testing" pauses appear, as exhibited by AD2. In the third session (Row 3), "drinking" bursts are longer and "bar testing" diminishes. By the sixth session (Row 4), with the "bar testing" still present, the interpellet "drinking" pattern is fully and permanently established. Rat AD4

Through the first session on FI60, "drinking" developed similarly to that of AD2 with "bar testing" present. However, thereafter "drinking" bursts gradually became short and scattered until "drinking" virtually disappeared.

Water consumption in the home cage during the postsession periods averaged over fourfold that of presession periods. $\mathrm{AD}_{2}$ averaged $1.3 \mathrm{ml}$ during presession periods, $4.3 \mathrm{ml}$ postsession; AD3, 1.4 and $5.3 \mathrm{ml}$; $\mathrm{AD} 4,1.1$ and $6.9 \mathrm{ml}$.

\section{DISCUSSION}

Schedule-induced nitrogen (or air) "drinking" appears almost identical to schedule-induced polydipsia. Falk and others (e.g., Stein, 1964) regard it as a postpellet phenomenon because drinking
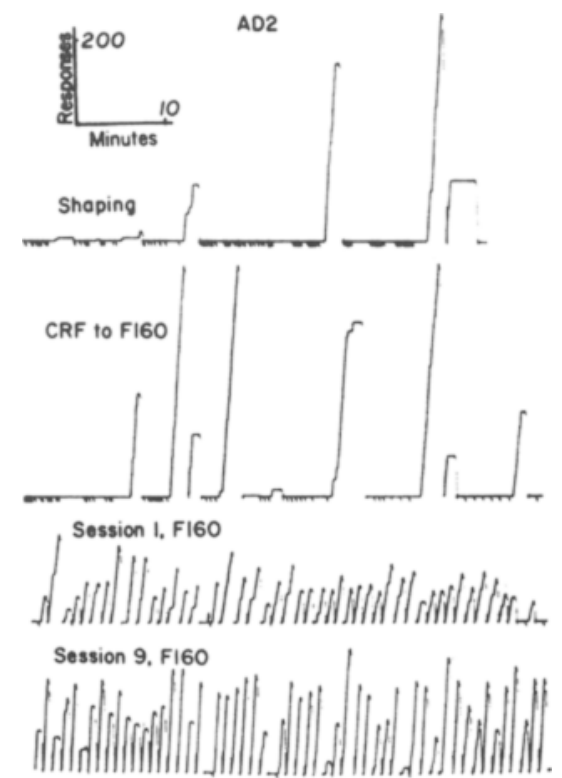

Fig. 1. Lick records for AD2. Each lick steps the recorder cumulatively, resets to baseline by receipt of a pellet. Hatch marks indicate pellets. 


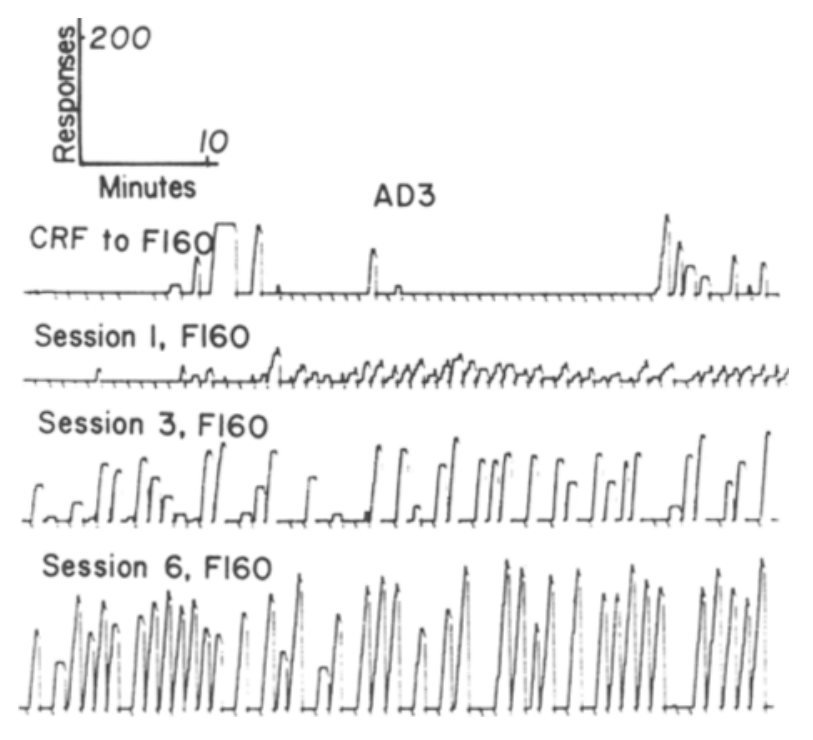

Fig. I. Lick records for AD3. Each lick steps the recorder cumulatively, resets to baseline by receipt of a pellet. Hatch marks indicate pellets.

immediately follows pellet receipt and ends typically well before the next pellet. Indeed, on FI60 some $30 \mathrm{sec}$ generally elapse between cessation of water drinking and the next pellet. ${ }^{3}$ In the present study, however, "drinking" bursts were most frequently followed immediately by a pellet. In the first full session on FI60, 60\%, 47\%, and $87 \%$ of the "drinking" bursts were followed within 2 or $3 \mathrm{sec}$ by a pellet for $\mathrm{AD} 2, \mathrm{AD} 3$, and AD4. By the ninth session this had increased to $65 \%$ and $62 \%$ for AD2 and AD3. Delays rarely exceeded $10 \mathrm{sec}$. One reason for this difference may be gastric limitations upon the amount of water ingested during a drinking burst. Nitrogen, imposing no such limitation, permits longer "drinking" bursts and resumption of "drinking" after nonreinforced bar presses ("bar testing"). Our examinations of schedule-induced wheelrunning data (Levitsky \& Collier, 1968) reveals that, like nitrogen "drinking," running occurs throughout the interval and is in terrupted by "bar testing."

Two factors most likely explain schedule-induced nitrogen "drinking": (1) Thirst seems at least partially involved. The home-cage water-consumption data indicate that ingestion of pellets invokes "thirst," perhaps via prandial water needs or local oral stimuli ("dry mouth"). That nitrogen invokes thirst is unlikely; air "drinking" actually retards water drinking in thirsty rats (Hendry \& Rasche, 1961), and AD4 continued drinking water in the postsession periods after having stopped "drinking" nitrogen. Since thirsty rats "drink" air (or nitrogen), the Ss might be expected to "drink" some nitrogen during the operant sessions. (2) The thirst-initiated nitrogen "drinks" could be adventitiously reinforced by the pellets and, since this response does not have to be learned, it would increase in frequency and vigor rapidly. The pellets may then function as cues for drinking even in the absence of thirst.

Falk (in press) dismisses adventitious reinforcement as explaining scheduleinduced polydipsia because a 15 -sec delay imposed between licking and the next pellet does not reduce drinking; however, another Falk experiment shows that "...welldeveloped polydipsia on an FI90 sec food schedule was progressively eliminated in a few days by changing the schedule to FI5 min..." We believe that the prior delays were not long enough.

Interpellet drinking also occurs with alcohol solutions (Lester, 1961) and even with 500 times the aversive concentration of quinine. ${ }^{4}$ These are probably also initiated by thirst and maintained by adventitious reinforcement, although with alcohol, maintenance may be supported also by its caloric value to a deprived rat. Wheel running (Levitsky \& Collier, 1968) and aggression (Gentry, 1968), quite dissimilar behaviors, also increase on intermittent food reinforcement. We suggest that any unlearned behavior, upon which reinforcement is not contingent, but which the testing conditions make pohable will respond to intermittent schedules in the same way. However, that these behaviors are probable must be demonstrated indepen. dently, or the explanation becomes circular. Thus, drinking by animals eating food (demonstrated by the postsession drinking (data), wheel running by food-deprived rats, and aggression by animals experiencing nonreinforcement (Azrin, Hutchinson, \& Rake, 1966) are all highly probable. Eating, however, is not probable in thirsty animals drinking water; significantly, neither Lester nor Collier could induce interreinforcement eating in rats bar pressing for water. ${ }^{5}$ Once a probable behavior occurs it may increase in frequency and vigor through adventitious reinforcement. In some cases, stimuli associated with the initiating factors may become cues for the behavior.

The "bar testing" seen in both nitrogen "drinking" and wheel running suggests that the animals may actually be working under two schedules simultaneously, using two responses: a bar-pressing schedule, programmed by $E$ and necessary for reinforcement, and a drinking, running, etc., schedule, animal-imposed and not necessary, but adventitiously reinforced.

\section{REFERENCES}

AZRIN, N. H., HUTCHINSON, R. R., \& RAKE, D. $F$.Extinction-induced aggression. Joumal of the Iexperimental Analysis of Behavior, 1966, 9, 191-204.

FALK, J. L. Production of polydipsia in normal rats by an intermittent food schedule. Science, 1961, 133, 195-196.

FALK, J. L. Conditions producing psychogenic polydipsia in animals. In: Neural regulation of food and water intake. Annals of the New Y ork Academy of Sciences, in press.

GENTRY, W. D. Fixed-ratio schedule-induced aggression. Journal of the Experimental Analy sis of Behavior, 1968, 11, 313-817.

HENDRY, D. P., \& RASCHE, R. H. Analysis of a new non-nutritive positive reinforcer based on thirst. Journal of Comparative \& Physiological Psychology, 1961, 54, 477-483.

LESTER, D. Self-maintenance of intoxication in the rat. Quarterly Joumal of Studies on Alcohol, 1961, 22, 223-231.

LEVITSKY, D., \& COLLiER, G. Scheduleinduced wheel running. Physiology \& Behavior, $1968,3,571-573$.

STEIN, L. Excessive drinking in the rat: Superstition or thirst? Joumal of Comparative \& Phy siological Psychology, 1964, 58, 237-242. NOTES

1. Supported in part by Grants MH-05655 and MH-11612 from the National Institute of Mental Health.

2. Reprint requests to $D$. Lester.

3. Lester, D., unpublished data, 1965.

4. Lester, D., unpublished data, 1966.

5. Lester, D., unpublished data; Collier, personal communication. 